\title{
Sporadic hemangioblastomas are characterized by cryptic VHL inactivation
}

\author{
Ganesh M Shankar ${ }^{1,5+}{ }^{,}$Amaro Taylor-Weiner ${ }^{5 \dagger}$, Nina Lelic ${ }^{1}$, Robert T Jones ${ }^{6}$, James C Kim², Joshua M Francis ${ }^{5}$, \\ Malak Abedalthagafi ${ }^{6}$, Lawrence F Borges ${ }^{1}$, Jean-Valery Coumans', William T Curry ${ }^{1}$, Brian V Nahed ${ }^{1}$, John H Shin ${ }^{1}$, \\ Sun Ha Paek ${ }^{7}$, Sung-Hye Park ${ }^{8}$, Chip Stewart ${ }^{5}$, Michael S Lawrence ${ }^{5}$,Kristian Cibulskis ${ }^{5}$, Aaron R Thorner ${ }^{9}$, \\ Paul Van Hummelen ${ }^{9}$, Anat O Stemmer-Rachamimov ${ }^{2}$, Tracy T Batchelor ${ }^{3}$, Scott L Carter ${ }^{5}$, Mai P Hoang ${ }^{2}$, \\ Sandro Santagata ${ }^{6}$, David N Louis ${ }^{2}$, Fred G Barker $\|^{1}$, Matthew Meyerson ${ }^{5,6,9,10}$, Gad Getz ${ }^{2,5}$, Priscilla K Brastianos ${ }^{4,5^{*}}$ \\ and Daniel P Cahill ${ }^{1 *}$
}

\begin{abstract}
Hemangioblastomas consist of 10-20\% neoplastic "stromal" cells within a vascular tumor cell mass of reactive pericytes, endothelium and lymphocytes. Familial cases of central nervous system hemangioblastoma uniformly result from mutations in the Von Hippel-Lindau (VHL) gene. In contrast, inactivation of VHL has been previously observed in only a minority of sporadic hemangioblastomas, suggesting an alternative genetic etiology. We performed deep-coverage DNA sequencing on 32 sporadic hemangioblastomas (whole exome discovery cohort $n=10$, validation $n=22$ ), followed by analysis of clonality, copy number alteration, and somatic mutation. We identified somatic mutation, loss of heterozygosity and/or deletion of VHL in 8 of 10 discovery cohort tumors. VHL inactivating events were ultimately detected in 78\% (25/32) of cases. No other gene was significantly mutated. Overall, deep-coverage sequence analysis techniques uncovered VHL alterations within the neoplastic fraction of these tumors at higher frequencies than previously reported. Our findings support the central role of VHL inactivation in the molecular pathogenesis of both familial and sporadic hemangioblastomas.
\end{abstract}

Keywords: Central nervous system, Hemangioblastoma, Deep sequencing, Somatic gene alterations, Von Hippel-Lindau gene, Hypoxia-inducible signaling

\section{Introduction}

Hemangioblastomas comprise $1-2.5 \%$ of primary intracranial and $7-10 \%$ of spinal cord tumors, with a benign pathology notable for neoplastic "stromal" cells embedded in a dense network of vascular channels [1]. These tumors are largely diploid with few chromosomal abnormalities [2,3], and have served as the prototypic lesions in the study of genomic drivers of hypoxia-mediated metabolism in cancer [4]. Approximately $25 \%$ of hemangioblastomas are a result of Von Hippel-Lindau (VHL) disease, which is inherited in an autosomal dominant manner through a germline inactivating mutation of the tumor suppressor gene $V H L$

\footnotetext{
* Correspondence: pbrastianos@mgh.harvard.edu; dcahill@partners.org ${ }^{\dagger}$ Equal contributors

${ }^{4}$ Departments of Hematology/Oncology, Massachusetts General Hospital, Boston, MA, USA

'Departments of Neurosurgery, Massachusetts General Hospital, Boston, MA, USA Full list of author information is available at the end of the article
}

on chromosome 3, with subsequent inactivation of the second allele by somatic mutation or gene loss in the neoplastic "stromal" cell. The clinical spectrum of VHL disease includes other neoplastic lesions, including retinal angiomatosis, pheochromocytoma and clear cell renal carcinoma.

Approximately $75 \%$ of hemangioblastomas are sporadic. VHL somatic mutations have been clearly identified in a fraction of sporadic tumors [2-10]. However, unlike in familial VHL disease, prior studies have indicated that the majority of sporadic hemangioblastomas do not have identifiable germline or somatic alterations in VHL (Table 1). This discrepancy stands in contrast to recent whole genome characterization of clear cell renal carcinomas, which have somatic mutations in the $V H L$ gene in $>80 \%$ of samples [11,12], focal deletion by loss of chromosome 3p26.1 in >90\% [13], or epigenetic silencing by promoter methylation in $7 \%$ [13]. 
Table 1 Findings from prior studies analyzing sporadic hemangioblastomas for somatic mutations, loss of heterozygosity or deletion of VHL

\begin{tabular}{|c|c|c|c|c|c|c|c|c|c|c|c|}
\hline \multirow[b]{2}{*}{ Reference } & \multirow[b]{2}{*}{ Patients } & \multicolumn{3}{|c|}{ Somatic mutation } & \multicolumn{3}{|c|}{ Loss of heterozygosity } & \multicolumn{3}{|l|}{ Deletion } & \multirow{2}{*}{$\begin{array}{l}\text { Biallelic VHL } \\
\text { inactivation (\%) }\end{array}$} \\
\hline & & Method & $\begin{array}{l}\text { Positive } \\
\text { cases }\end{array}$ & $\begin{array}{l}\text { Rate of somatic } \\
\text { mutation (\%) }\end{array}$ & Method & Positive cases & $\begin{array}{l}\text { Rate of } \\
\text { LOH (\%) }\end{array}$ & Method & Positive cases & $\begin{array}{l}\text { Rate of } \\
\text { deletion (\%) }\end{array}$ & \\
\hline Kanno et al. [6] & 13 & Sanger & $3 / 13$ & 23 & NA & NA & NA & NA & NA & NA & NA \\
\hline Oberstrass et al. [7] & 18 & Sanger & $8 / 18$ & 44 & NA & NA & NA & NA & NA & NA & NA \\
\hline Tse et al. [5] & 5 & Sanger & $2 / 5$ & 40 & $\begin{array}{l}\text { polymorphic } \\
\text { markers }\end{array}$ & $1 / 2$ & 50 & NA & NA & NA & 10 \\
\hline Olschwang et al. [8] & 18 & Sanger & $2 / 18$ & 11 & NA & NA & NA & NA & NA & NA & NA \\
\hline Lee et al. [9] & 20 & Sanger & $2 / 20$ & 10 & $\begin{array}{l}\text { polymorphic } \\
\text { markers }\end{array}$ & $10 / 19$ & 53 & NA & NA & NA & 11 \\
\hline Glasker et al. [3] & 13 & Sanger & $3 / 13$ & 23 & $\begin{array}{l}\text { polymorphic } \\
\text { markers }\end{array}$ & $5 / 13$ & 38 & NA & NA & NA & 8 \\
\hline Gijtenbeek et al. [2] & 16 & Sanger & $5 / 16$ & 31 & NA & NA & NA & CGH & $11 / 16$ & 69 & 19 \\
\hline Lemeta et al. [10] & 11 & NA & NA & NA & $\begin{array}{l}\text { polymorphic } \\
\text { markers }\end{array}$ & $11 / 11$ & 100 & CGH & $2 / 11$ & 18 & 18 \\
\hline
\end{tabular}


We considered two possibilities for this difference between the reported frequency of mutations in VHL between familial and sporadic hemangioblastomas. The first explanation is that sporadic cases of hemangioblastoma may develop via alterations in genes involved in hypoxia-sensing pathways other than VHL itself that also result in a histologically-identical phenotype of exuberant angiogenesis. A candidate gene for such an alteration is TCEB1, which encodes the required VHL binding partner elongin $\mathrm{C}$ and, in the recent genomic sequencing of clear cell renal carcinoma was found to be somatically mutated in the minority of cases that do not harbor VHL mutations [14]. A second explanation is that prior bulk sequencing techniques were technically limited in capturing the full extent of VHL inactivation. Neoplastic "stromal" cells comprise roughly 10-20\% of the hemangioblastoma tumor cell mass with the remainder consisting of pericytes, vascular endothelium and other nucleated cells, such as lymphocytes, that are present in the vascular channels [15]. Given the relatively low purity of neoplastic cells, previous studies may not have detected the entire spectrum of alterations in VHL.

The emergence of next generation sequencing technologies has rapidly accelerated the discovery of somatic alterations in cancer genes, by exploiting greater depth-ofcoverage to increase the sensitivity of detection within low purity samples [13,16-22]. Application of these techniques to hemangioblastomas can comprehensively examine the role of VHL across the spectrum of this disease. In addition, whether hemangioblastomas form from an embryologically arrested "hemangioblast" stem cell that subsequently differentiates into the discrete constituent cell types that support the architecture of this vascular tumor [1,23-25] is unclear. While developmental studies have shown a common precursor of the differentiated cell types (endothelial, stromal) found in the hemangioblastoma cell mass, whether neoplastic cells contribute to these different populations was not well-characterized. By analyzing the extent of genomic alterations and their subclonal and clonal status within the tumor mass of sporadic hemangioblastomas, this issue can be addressed. In this study, we characterize sporadic hemangioblastomas of cerebellum and spinal cord by whole exome sequencing and deep-coverage sequence analysis.

\section{Materials and methods}

\section{Sample acquisition}

This study was approved by the Institutional Review Board at the hospitals providing specimens. Written informed consent was obtained for all samples undergoing whole exome sequencing. The discovery and validation cohorts of sporadic hemangioblastomas involving the cerebellum and spinal cord were obtained from patients treated at Massachusetts General Hospital (MGH, Boston MA), Brigham and Women's Hospital (BWH, Boston MA), and Seoul National University (South Korea). Patients were identified as likely sporadic hemangioblastomas based on (1) prior testing that was negative for germline VHL mutations by sequencing of the coding regions (exons 1-3), (2) lack of family history of hemangioblastomas or VHL disease, and/or (3) lack of other stigmata of VHL disease, such as renal cancer, pheochromocytoma, or retinal angiomas. Pathology was verified by the Departments of Pathology at $\mathrm{MGH}$ and $\mathrm{BWH}$ (DNL, SS and MA) and tumor rich areas were microdissected.

\section{Tumor sequencing}

DNA was extracted from FFPE tumor specimens and matching peripheral blood samples using standard techniques (QIAamp, Qiagen) and quantified by PicoGreen dye (Invitrogen). Whole exome sequencing was performed by hybrid capture and next-generation sequencing as described previously [26]. In brief, DNA was fragmented by sonication (Covaris Inc., Woburn, MA) to $150 \mathrm{bp}$ and further purified using Agencourt AMPure XP beads. $50 \mathrm{ng}$ of size-selected DNA was then ligated to specific adaptors during library preparation (Illumina TruSeq, Illumina Inc., San Diego, CA). Each library was made with samplespecific barcodes and quantified by quantitative PCR (Kapa Biosystems, Inc., Woburn, MA), and two libraries were pooled to a total of $500 \mathrm{ng}$ for exome enrichment using the Agilent SureSelect hybrid capture kit (Whole Exome_v1.1; Agilent Technologies, Santa Clara, CA). Several captures were pooled further and sequenced in one or more lanes to a final equivalent of two exomes per lane on a HiSeq 2500 system (Illumina Inc, San Diego, CA).

The validation cohort was sequenced for 560 cancerassociated genes and 39 translocations previously implicated in cancer (Additional file 1: Table S1). Briefly, DNA was sonicated to achieve an average fragment size of $250 \mathrm{bp}$, size selected and barcoded. Multiplexed pools were hybridized with biotinylated baits (Agilent SureSelect) designed to capture exonic sequences, including those of $V H L$ and $A R I D 1 B$. The captures were sequenced on the Illumina HiSeq 2500 in Rapid Run Mode.

Separately, Sanger sequencing of the TCEB1 Tyr79Cys hotspot, and the promoter and exon 1 of $V H L$, was performed on PCR amplified products from tumor genomic DNA. Chromatograms were manually reviewed to evaluate for the presence of somatic mutations, which may be represented as a minor allele.

\section{Mutation analysis}

Somatic variant, germline variant, and small deletions and insertion calling was performed within the Firehose environment at the Broad Institute with the previously published MuTect, MapReduce, and Indelocator algorithms [27-30]. Pindel, an algorithm for detecting insertions and deletions (indels) [31], was used to detect indels in the coding regions of $V H L$. Because the samples were all obtained from 
formalin fixed, paraffin embedded (FFPE) pathology specimens, we applied a filtering algorithm to reduce the number of artifactual mutations introduced by FFPE [32]. The FFPE filter consists of two steps. First, the filter estimates the component of total sequencing error rate due to FFPE artifacts in a CpG island by scanning all reference $C$ (or G) sites counting sites sequenced as T (or A) in the two possible read pair orientations. Second, the orientation of each $\mathrm{C}>\mathrm{T}$ ( or $\mathrm{G}>\mathrm{A}$ ) mutation is compared to a model of balanced read pair orientation (binomial with $\mathrm{p}=0.5$ : no artifact) and a biased orientation characteristic of FFPE artifacts (binomial with $p=0.96$ ), as FFPE-induced artifacts affect one of the DNA strands. The filter removes mutations consistent with the FFPE orientation bias to the degree where less than $1 \%$ of the surviving mutations in a given sample are consistent with FFPE artifacts. Significance of mutated genes was determined by MutSigCV [33].

\section{Copy number and rearrangement analysis}

Segmented copy data was obtained using copy number ratios. These were calculated as the ratio of tumor read depth to the average read depth observed in a panel of normal samples. Subsequently we converted the copy ratio data to allelic ratio, which allows for detection of copy neutral $\mathrm{LOH}$ and gives another constraint on copy number alterations. ABSOLUTE [22] was used to estimate sample purity and ploidy and then calculate cancer cell fraction (inferred percentage of neoplastic nuclei that harbor a given mutation) and cell copy number of mutations and local DNA copy changes. Rearrangements were determined by the dRanger and BreakPointer algorithms [34].

\section{Loss of heterozygosity analysis of validation cohort}

To assess whether $V H L$ in our validation cohort was deleted or in copy neutral loss of heterozygosity, we examined the distribution of allele fractions of heterozygous mutations in the mix of reported somatic and germline variants. In a diploid state (ploidy $=2$ ) germline heterozygous sites should be represented by $50 \%$ allele fraction. When samples gain or lose a copy, the allele fraction of those sites will shift in relationship to the purity of the tumor. In order to determine the copy state of each sample we identified peaks in the probability density function (pdf) of allele fractions:

$$
p d f(C h r 3 p)=\sum_{m} p d f(a f, \operatorname{alt}(m)+1, \operatorname{ref}(m)+1)
$$

Where $a f$ is the true allele fraction between 0 and 1 , and alt is the alternate allele counts, ref is the reference allele count, and $m$ is each single nucleotide variant detected along chromosome 3p. Samples demonstrating allelic fractions with bimodal distributions were called positive for a deletion or copy neutral loss of heterozygosity.
For samples demonstrating allelic shift, tumor purity $\left(\mathrm{P}_{\mathrm{T}}\right)$ was further estimated from the allele fraction of the upper allele $\left(X_{\mathrm{A}}\right)$ in the two following scenarios.

(1)if the $\mathrm{LOH}$ event represents a copy neutral event, then the tumor purity $\left(\mathrm{P}_{\mathrm{T}}\right)$ is given by the following equation:

$P_{T}=2 * X_{A}$

(2)if the $\mathrm{LOH}$ event was a result of haploidization, then the tumor purity is given by:

$$
P_{T}=\frac{2 * X_{A}-1}{X_{A}}
$$

\section{Immunohistochemistry}

Five micron sections of the FFPE specimens from the discovery cohort were prepared and stained for HIF1- $\alpha$ (NB100-131, Novus Biologicals), VEGF (SC-152, Santa Cruz Biotechnology), or PDGFR- $\beta$ (AB32570, Abcam) by protocols described in the product data sheets. IHC was reviewed and scored by MPH.

\section{Results}

We performed whole exome sequencing (WES) of 10 sporadic hemangioblastomas for our discovery cohort and targeted sequencing of 22 sporadic hemangioblastomas for our validation cohort. Estimation of neoplastic stromal cell content was $10-30 \%$ at pathology review (Additional file 2: Figure S1). The average age of the patients in the combined cohorts was 53.3 years with 23 tumors resected from the cerebellum and 9 from the spinal cord (Table 2). WES of germline DNA from the discovery cohort did not reveal any $V H L$ mutations, indicating that these patients do not have VHL disease and that the tumors we evaluated are bona fide sporadic hemangioblastomas. The exomes of tumor specimens in the discovery cohort were covered at a mean depth of $116 \times$ (Additional file 1: Table S2). We did not detect any rearrangements in the discovery cohort using previously reported algorithms, which can detect events that occur close to exons [34].

Copy number analysis of the WES data revealed recurrent loss of chromosome 3, but otherwise the genomes of tumors in the discovery cohort were diploid (Figure 1). By combining coverage ratio and allelic data to determine regions of somatic copy change and copy neutral loss of heterozygosity (copy neutral-LOH), we found focal hemizygous deletions of chromosome $3 p$ resulting in loss of the VHL locus in 3 samples and hemizygous deletion of the entire chromosome $3 p$ arm in 4 samples of the discovery cohort (Additional file 3: Figure S2, Additional file 1: Table S3). One sample was found to 


\begin{tabular}{|c|c|c|}
\hline & Discovery $(n=10)$ & Validation $(n=22)$ \\
\hline Average Age (IQR) & $52(44-61)$ & $54(44-63)$ \\
\hline \multicolumn{3}{|l|}{ Location } \\
\hline Cerebellum & 8 & 15 \\
\hline Spinal cord & 2 & 7 \\
\hline \multicolumn{3}{|l|}{ Gender } \\
\hline Male & 7 & 9 \\
\hline Female & 3 & 13 \\
\hline Prior $V H L$ testing & 1 & 5 \\
\hline Additional VHL-related lesions & 0 & 0 \\
\hline
\end{tabular}

Interquartile range (IQR) for age of patients is represented in parentheses. Patients who had undergone prior clinical testing for germline VHL mutations are listed. No patients included in either cohort were noted to have canonical VHL-related lesions, including retinal hemangioblastomas, pancreatic lesions, pheochromocytomas, endolymphatic sac tumors, renal cysts or clear cell renal carcinoma.

have focal copy neutral LOH of the VHL locus and an additional sample was found to have a copy neutral $\mathrm{LOH}$ of the entire chromosome $3 \mathrm{p}$ arm. Deletion of chromosome 8 was noted in 2 specimens and deletion of chromosome 6 in one specimen.

To identify somatic mutations in the WES data, a filter was first applied to exclude artifact mutations introduced by the processing of formalin-fixed, paraffin-embedded (FFPE) specimens, which are characterized by artificially induced $\mathrm{C}>\mathrm{T}$ [32]. These artifact mutations are distinct from real $\mathrm{CpG}>\mathrm{TpG}$ mutations, which dominate in most cancers. The FFPE filter accordingly removed 10 spurious mutations (Additional file 4: Figure S3).

The sequence data was then post-processed with MuTect [27] to identify true somatic mutations. The average overall mutation rate was $1.5 / \mathrm{Mb}$ with a total of 398 nonsynonymous mutations and 118 synonymous mutations detected among the 10 samples (Additional file 1: Table S4). In comparison to other adult solid tumors, sporadic hemangioblastomas have a relatively low somatic mutation rate (Figure 2a), but one that is similar to other intracranial neoplasms with a tendency to local recurrence but not widespread dissemination, such as meningiomas $(1.6 / \mathrm{Mb})[26,35]$ and craniopharyngiomas $(0.9 / \mathrm{Mb})[19]$. A total of 377 genes were found to have at least one non-synonymous mutation in the discovery set (Additional file 1: Table S4). Of these, $V H L$ was mutated in 5 samples with an allele fraction ranging from $18-21 \%$ and cancer cell fraction from $76-100 \%$, suggesting a clonal somatic mutation carried by the subpopulation of neoplastic "stromal" cells. VHL was the only gene found as statistically significant with respect to the false discovery rate by MutSigCV [27] (Figure $2 \mathrm{~b}, \mathrm{q}<0.1$ ), suggesting that no other gene is mutated at a similar rate.
Because exon 1 of $V H L$ was covered at a lower mean depth $(13 \times)$ than exons $2(213 \times)$ and $3(51 \times)$ (Figure $2 b)$, the promoter region and exon 1 were separately PCR amplified and Sanger sequenced for the four specimens that did not demonstrate evidence for biallelic $V H L$ inactivation. None of these specimens, for which exon 1 was initially covered at a mean of $7.4 \times$, demonstrated somatic mutations in the promoter region or exon 1 of $V H L$ by Sanger sequencing, although this method is not highly sensitive for detection of mutations with low allelic fractions. Of note, two missense mutations in ARID1B were identified in two separate hemangioblastomas, at amino acid positions 647 and 651, with predicted allelic fractions of $2-6 \%$ and cancer cell fraction of $8-32 \%$, suggesting subclonality.

When mutations, deletions or $\mathrm{LOH}$ events involving the VHL locus are taken together, the discovery cohort of sporadic hemangioblastomas demonstrate biallelic inactivation of $V H L$ in 6 of 10 cases and inactivation of at least a single allele of $V H L$ in 8 of 10 cases (Figure 3).

The validation cohort consisted of 22 sporadic hemangioblastomas, for which the exons of 560 genes (including $V H L$ and $A R I D 1 B$ ) and 39 translocations previously implicated in cancer were sequenced at an average depth of 182x. The validation cohort revealed $\mathrm{LOH}$ of chromosome $3 p$ in 15 of the 22 samples (Additional file 5: Figure S4). Tumor purity was estimated for the validation specimen demonstrating $\mathrm{LOH}$ and ranged from $8-57 \%$ (Additional file 1: Table S5). $V H L$ was sequenced at a mean depth of $87 x$ in this cohort and eleven specimens were found to have non-synonymous mutations in VHL (Additional file 1: Table S6). One of these specimens was noted to have a frame shift 22-nucleotide tandem duplication in exon 3 within 8 codons of the stop codon. Of note, while the validation specimens were selected as representing sporadic hemangioblastomas by clinical information and germline testing for most, it is possible that up to $10 \%$ of these patients without matched blood may have germline $V H L$ mutations $[7,8]$. Of specimens in the validation cohort that were found to have a non-synonymous mutation in $V H L, 82 \%$ also had LOH (Figure 4). No nonsynonymous mutations in $A R I D 1 B$ were detected in the validation set. In addition, no TCEB1 Tyr79Cys mutations were detected in any of the 32 hemangioblastomas in this study.

Prior studies have raised the possibility that hemangioblastomas arise from an embryologically arrested hemangioblast capable of differentiating into any of the cell types that comprise this vascular network, including pericytes, vascular endothelium, and even erythrocyte islands [1,23-25,36,37]. To assess the tumor cell fraction, we used ABSOLUTE, an algorithm which estimates tumor purity and ploidy allowing for calculation of cell copy number and cancer cell fraction of local DNA segments and 


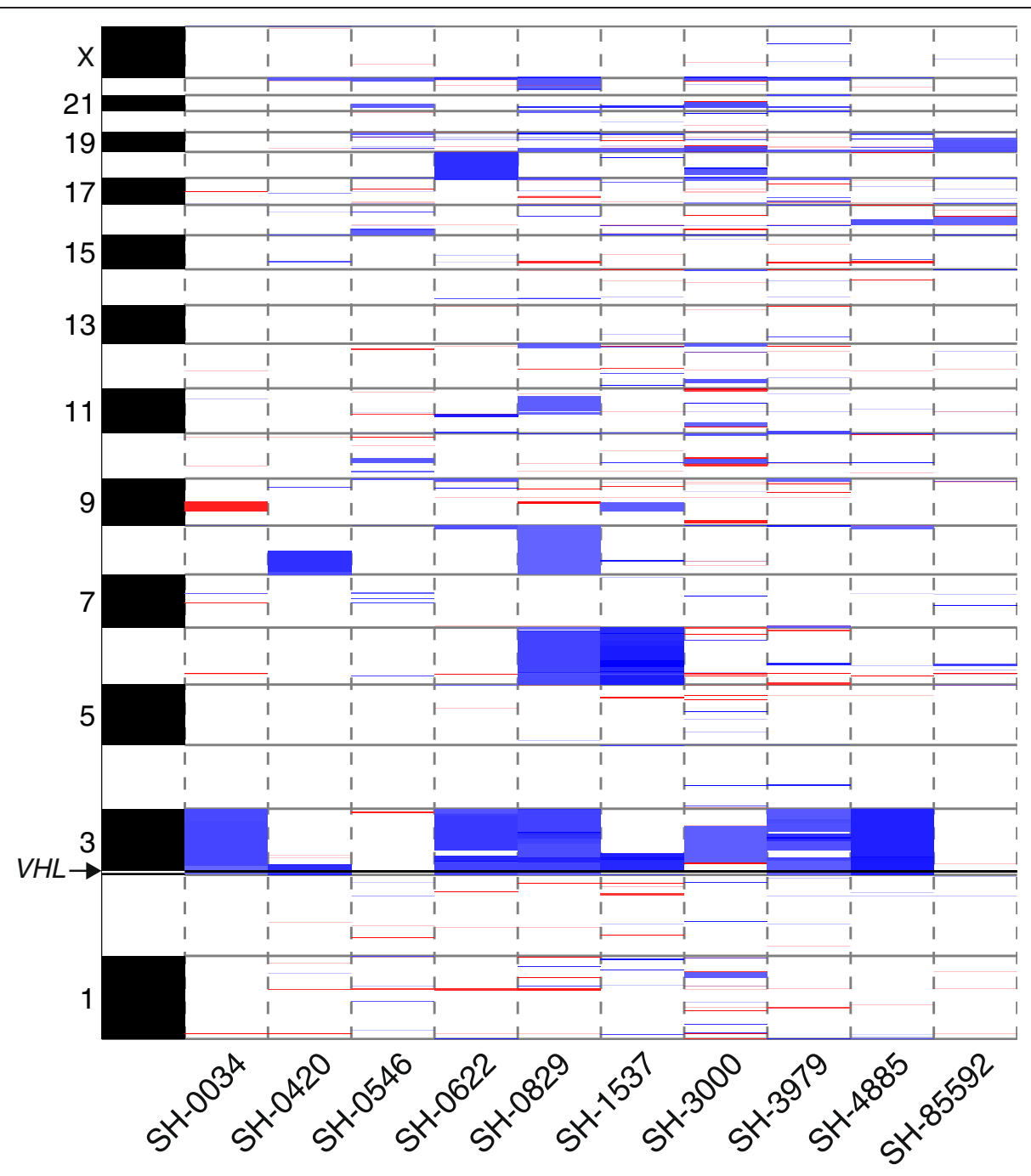

Figure 1 Sporadic hemangioblastomas demonstrate recurrent losses of chromosome 3. Segmentation of coverage and allelic data reveals recurrent deletion and LOH (blue) of chromosome 3. Each sample is represented as a column with evidence for amplifications denoted as red (allelic threshold 2.15-2.5) and deletions as blue (allelic threshold 1.5-1.85) along chromosomes which are represented as rows. The VHL locus is marked by the horizontal black line crossing chromosome 3p25 (indicated by arrow).

mutations [22]. Similar algorithms were used recently for analyzing craniopharyngiomas, in which the fraction of neoplastic cells within the tumor bulk can be $<10 \%$ [19]. Tumor purity of the discovery cohort determined by ABSOLUTE ranged from 9-49\% (median 33\%) (Additional file 1: Table S2), which corresponds to the neoplastic cell content of sporadic hemangioblastomas (Figure 5). This intercellular genomic heterogeneity suggests that the majority of nucleated cells in the tumor mass do not arise from a common ancestral clone, supporting the model that the tumor mass histology is a consequence of reactive angiogenesis resulting from paracrine signaling mediated by the VHL-deficient HIF1 $\alpha$-expressing "stromal" cells.

\section{Discussion}

$V H L$ mutations have been previously detected in sporadic hemangioblastomas [2-10]. Our study is the first to comprehensively set an upper bound on the frequency of other alterations in hemangioblastoma formation, and further confirm that $V H L$ alterations can be detected in the vast majority of hemangioblastomas, establishing $V H L$ inactivation as the central event in formation of this tumor. Based on the implications of prior work, these findings were one of the possible anticipated results in this prototypic tumor type, and were facilitated by next generation sequencing techniques. In addition, utilization of this technology allowed for quantification of allelic frequency, revealing the cell non-autonomous role of $V H L$-inactivated 


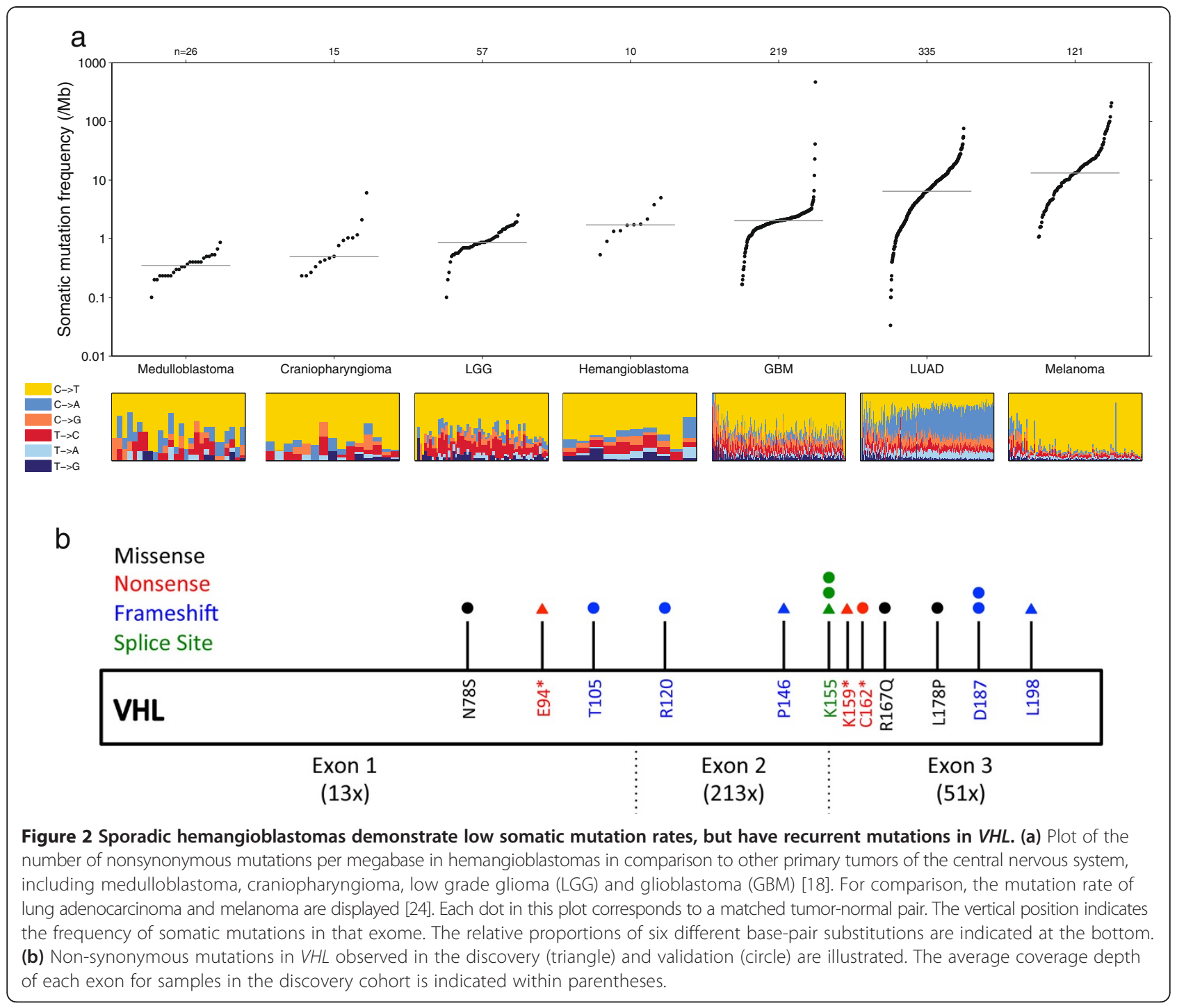

hemangioblasts/stromal cells driving and sustaining the tumor cell mass via recruitment of intermixed normal endothelial cells.

Biallelic $V H L$ inactivation in hemangioblastoma results in insufficient degradation of HIF- $1 \alpha$, which then results in the inappropriate transcription of effectors normally expressed in hypoxic states, such as vascular endothelial growth factor (VEGF) or platelet derived growth factor B (PDGF B) [38]. Accordingly, the tumor cell mass is composed largely of non-neoplastic endothelial cells and surrounding pericytes, with only a minor component consisting of neoplastic "stromal" cells that actually bear driver mutations. The process of tumorigenesis is thus driven by a subpopulation of neoplastic cells that recruit and interact with diverse cellular types to form the tumor mass $[39,40]$. Genomic analyses that do not sufficiently account for such cell-type purity issues can incompletely characterize the spectrum of alterations within the neoplastic cellular compartment. Sporadic hemangioblastomas therefore offered an enticing opportunity to use the most current analytics in cancer genomics to uncover cryptic driver alterations, which may be present in only a minor subpopulation of the overall tumor mass, evading detection by prior bulk tissue analyses.

As predicted by the benign clinico-pathologic features, hemangioblastomas were notable for a relatively low frequency of mutations. Within this context of infrequent mutations and copy number alterations, we found a markedly high prevalence of recurrent somatic mutations (50\%) and $\mathrm{LOH}$ of the gene locus on chromosome $3 p$ (72\%). Together, these alterations account for biallelic inactivation of $V H L$ in $47 \%$ and an inactivating alteration in at least one allele in $78 \%$ of sporadic hemangioblastomas. We detected these alterations in specimens with tumor cell fractions as low as $9 \%$. It is possible that we could have captured an even higher prevalence of $V H L$ inactivation 


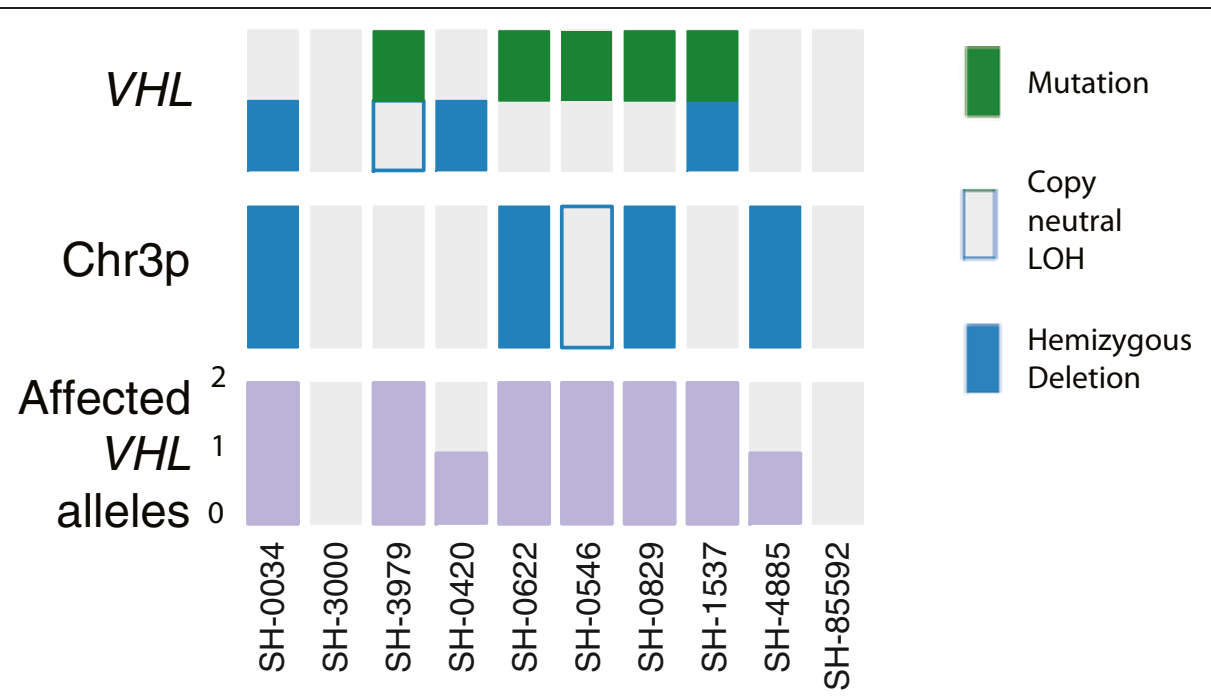

Figure 3 Whole exome sequencing of sporadic cerebellar and spinal cord hemangioblastomas reveals recurrent VHL inactivation. The VHL locus was noted to have non-synonymous mutations (green), copy neutral LOH (empty blue box), or hemizygous deletion (filled blue box) in $8 / 10$ samples in the discovery cohort.
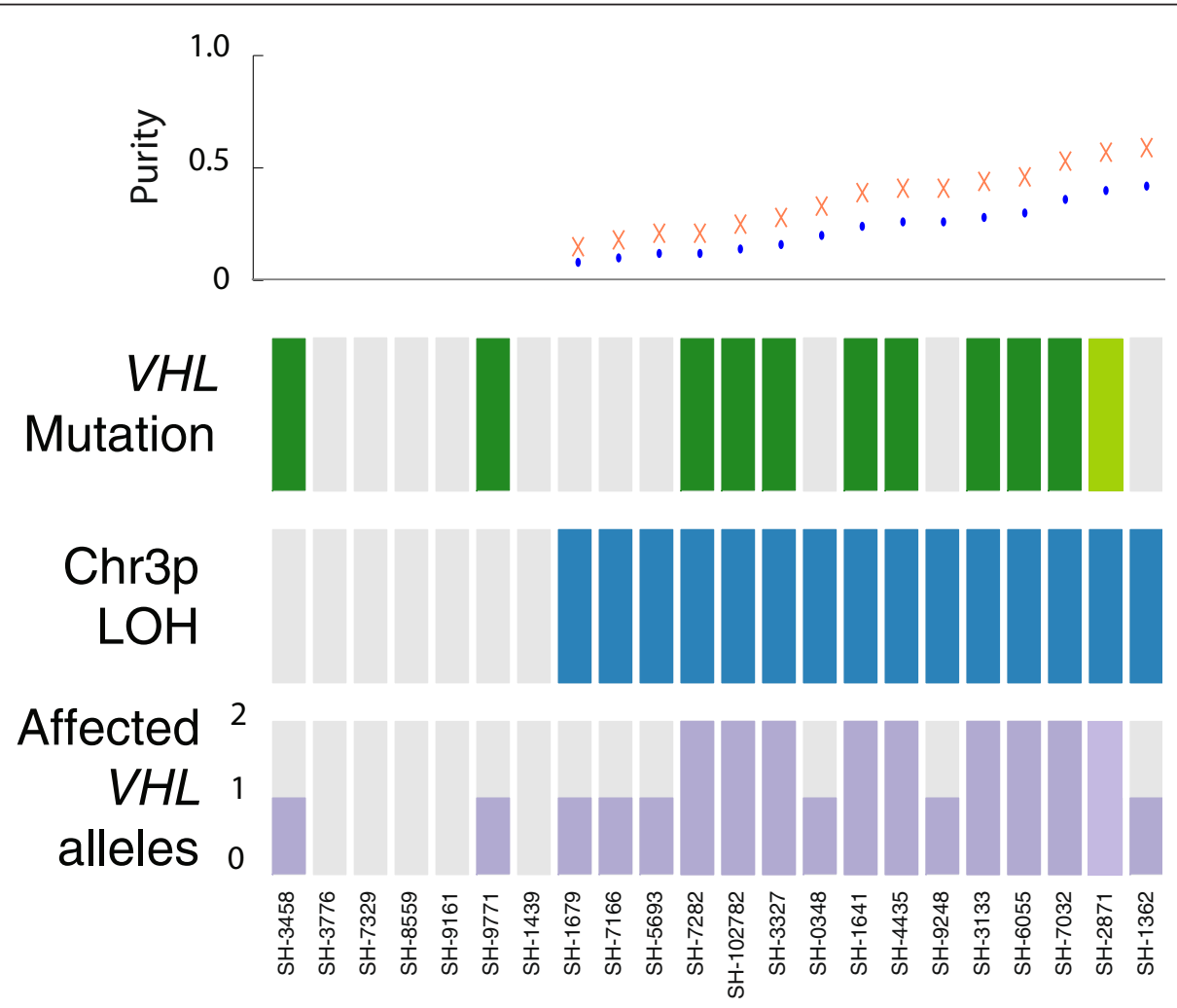

Figure 4 High frequency recurrent somatic events involving the $V H L$ locus are confirmed in a validation cohort of sporadic hemangioblastomas. The validation cohort was noted to have non-synonymous mutations (green) or LOH (blue) of the VHL allele in 17/22 specimens. Sample SH-2871 was noted by Pindel to have 22-nucleotide tandem duplication in exon 3 (light green). A range for tumor purity in the validation cohort was imputed from LOH as a function of either a copy neutral event (blue dot) or haploidization (orange cross). 


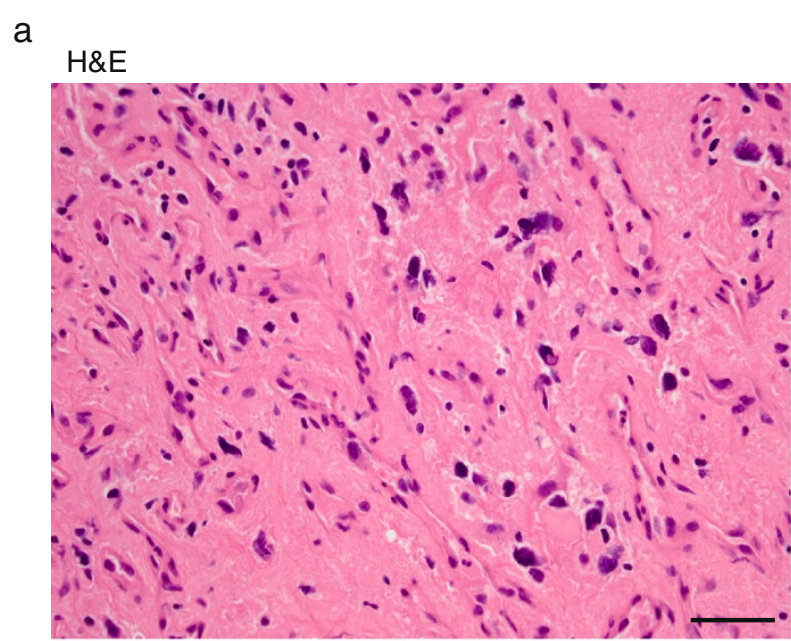

C

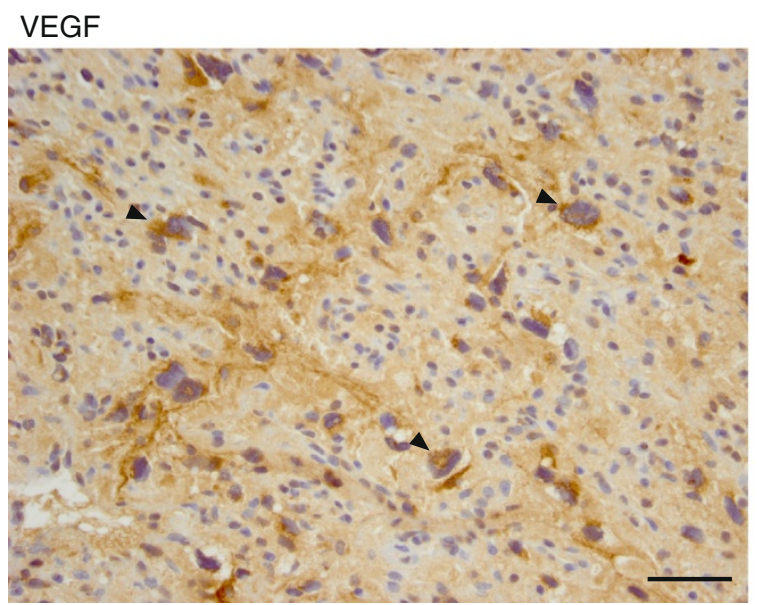

b

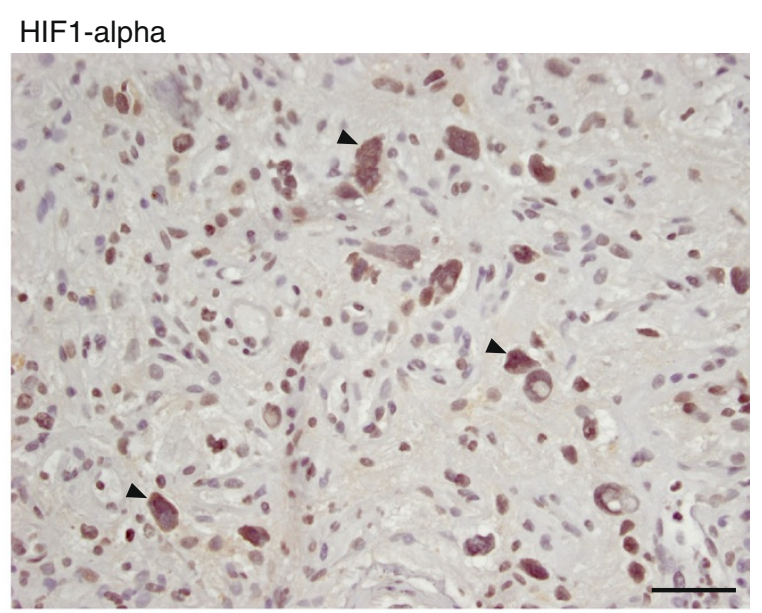

d

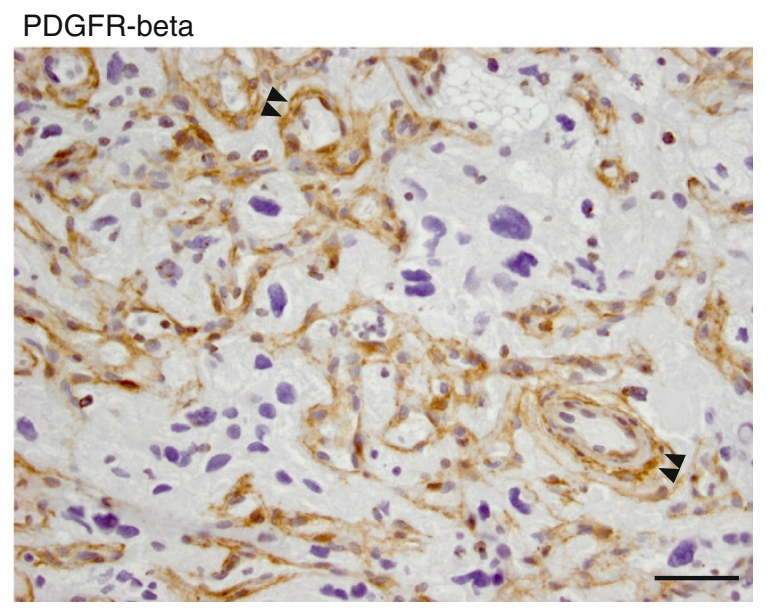

Figure 5 Histologically distinct cell types in hemangioblastomas do not arise from a common ancestral clone. "Representative images of sample SH-0622 acquired at 400x of (a) H+E and IHC for (b) HIF1-a, (c) VEGF, and (d) PDGFR- $\beta$ reveal heterogenous cell types in this tumor characterized by a rich vascular network. Arrowheads indicate that the stromal cells demonstrate increased cytoplasmic staining for HIF1-alpha and VEGF, whereas the double arrowheads highlight PDGFR-beta protein restricted to vascular endothelium. Scale bar is $25 \mu \mathrm{m}$.

via somatic mutation or $\mathrm{LOH}$ with deeper sequencing across $V H L$ in its entirety.

Prior studies have reported the presence of mutations in $V H L$ in 10 to $44 \%$ of sporadic hemangioblastoma [4]. The frequency of aneuploidy of chromosome 3 has ranged from 18 to $69 \%$ in these sporadic tumors [2,3]. One study identified concurrent somatic mutation and LOH of $V H L$ in only 1 of 13 sporadic hemangioblastomas [3] and another study identified missense mutations with deletion of $V H L$ by comparative genomic hybridization in only 2 of 16 sporadic hemangioblastomas [2]. This is likely a consequence of lower VHL mutant allele fractions confined to the neoplastic "stromal" cells in sporadic hemangioblastomas, as compared to familial tumors that are characterized by heterozygous germline $V H L$ alterations.
Mutations in ARID1B, which behaves as a tumor suppressor in other cancers [41-44], were detected in this study in $20 \%$ of the discovery cohort, a level that did not reach statistical significance by our analysis. Furthermore, the mutations were present with allelic fractions of only 2$6 \%$ and these lesions were found to be subclonal. Further analysis is needed to determine whether such subclonal variants are functionally important in supporting the development of sporadic hemangioblastomas $[45,46]$.

$V H L$ inactivation in the pathogenesis of sporadic hemangioblastoma mirrors the $V H L$ alterations seen in benign renal cysts, which may serve as precursors of clear cell renal cancer [47]. These cysts are notable for biallelic $V H L$ inactivation in renal tubular epithelial cells; whereas, clear cell renal cancer is additionally characterized by 
mutations in genes involved in the PTEN-mTOR pathway $[13,14]$. Similar to benign renal cysts, hemangioblastomas rarely demonstrate aggressive malignant features, and we did not detect additional clonal genetic drivers in hemangioblastomas, including other candidate genomic loci on chromosome 3p of BAP1, SETD2, and PBRM1 implicated in clear cell renal carcinoma.

The analysis of tumor purity by ABSOLUTE also demonstrates that the extent of $V H L$ inactivation in these tumors parallels "stromal" cell content estimated by IHC, rather than representing a homogenous genome that would characterize a tumor cell mass entirely derived from an ancestral hemangioblast clone. This important distinction lends further support to the model that stromal cells are genetically unique in $V H L$ deficiency and stimulate reactive angiogenesis by recruiting normal endothelial cells via pseudo-hypoxia mediated paracrine signaling. This model contrasts with the alternate proposed pathway of an embryologically arrested "hemangioblast" ancestral clone that trans-differentiates into the various cell types contained in the tumor $[24,25,36]$.

In summary, we find that inactivation of $V H L$ is highly recurrent and characteristic of the majority of sporadic hemangioblastomas. In addition, we do not detect other common recurrent somatic mutations in these tumors. These data therefore confirm the central role of $V H L$ inactivation in all hemangioblastomas, suggesting that treatment strategies for both familial and sporadic cases could be uniformly considered, as VHL loss in the neoplastic subpopulation likely orchestrates the architecture of these tumors. For example, VEGF inhibitors have been used in cases of multifocal familial hemangioblastomas with treatment responses [48,49]; their use in surgically-challenging sporadic disease should be considered. Advances in deepcoverage sequence analysis have thus resulted in a more complete understanding of the molecular basis of this canonical cancer type, and hold promise for the discovery of similarly cryptic drivers of tumorigenesis in other cancers with complex and diverse cellular composition.

\section{Conclusions}

In this study, we performed whole exome sequencing of matched tumor-normal specimens of sporadic hemangioblastoma and found that $V H L$ inactivation is more highly prevalent in this disease process than previously noted and that no other gene alteration was identified at a statistically significant level in these tumors. High depth sequencing was required to unmask the low allelic fraction of $V H L$ mutations and copy number alterations found in the neoplastic "stromal" cells, which are present only in a fraction of cells comprising the overall tumor mass. The central role of $V H L$ in the formation of sporadic hemangioblastomas suggests that the approach to these tumors can be universally considered as a single entity together with familial cases, which arise as a result of VHL disease.

\section{Additional files}

Additional file 1: Table S1. List of exomes and translocations that were sequenced in the validation cohort. Coding regions of 560 genes and 39 translocations previously implicated in cancer were targeted in the analysis of this cohort. Table S2. Mean target coverage data in discovery cohort of tumor and matched normal specimen. Tumor purity represented as a percentage was estimated by ABSOLUTE. Table S3. Allelic copy ratio of sequenced exome segments in discovery cohort. Table S4. Composite table of somatic mutations detected in discovery cohort by whole exome sequencing. CCF column indicates fraction of neoplastic cells that harbor the mutation as determined by ABSOLUTE. Table S5. Loss of heterozygosity analysis of validation cohort. As described in Materials and methods, tumor purity was estimated from the fraction of the upper allele in the two following scenarios: (1) if the LOH event represents a copy neutral event or (2) if the LOH event was a result of haploidization. Table S6. Composite table of the somatic mutations detected in the validation cohort by targeted sequencing of 560 cancer associated genes (OncoPanel).

Additional file 2: Figure S1. Representative histopathology of sporadic hemangioblastoma sequenced in this study. Hematoxylin and eosin stain of sporadic hemangioblastoma at 200x magnification (scale bar $=50 \mu \mathrm{m}$ ) reveals cellular heterogeneity consisting of pericytes, vascular endothelium, blood cells, and the neoplastic "stromal" cells which are cells with foamy cytoplasm representing 10-30\% of the overall mass.

Additional file 3: Figure S2. Segmentation of coverage and allelic data reveals recurrent deletion and LOH (blue) of the VHL locus in the discovery cohort. Darker shades of blue indicate increased copy loss. Each row represents a sample within the discovery cohort. The VHL locus along chromosome $3 p$ is indicated by the red arrow.

Additional file 4: Figure S3. Two dimension histogram of SNV read strand orientation bias (i_ffpe_F) vs. alternate allele counts (alt counts) in the $\mathrm{C}>\mathrm{T}$ (or complement $\mathrm{G}>\mathrm{A}$ ) mutation mode. The color code on the right indicates the number of mutations falling into a given bin. The histogram at the bottom is a projection of all mutation to the i_ffpe_F axis and the histogram along the left is a projection onto alt allele counts. Real mutations are expected to have a symmetric distribution (binomial distribution with probablility 0.5 at each alt count) but there is a clear bias toward i_ffpe_F values approaching 1.0, particularly at the lowest allele counts. This bias is a result of the single strand damage characteristic of FFPE. The filter removes mutations occurring in the lower right section, with a threshold optimized to leave at most one percent of the surviving mutations arising from FFPE artifact [32].

Additional file 5: Figure S4. Sporadic hemangioblastomas in the validation cohort display recurrent loss of heterozygosity of chromosome $3 p$. The frequency of allele fractions of mutations on chromosome $3 p$ were plotted and loss of heterozygosity was identified in 15 samples where allelic shift (vertical red and blue lines) was noted from the expected distribution centered at 0.5 (vertical black line).

\section{Competing interests}

The authors declare that they have no competing interests.

\section{Authors' contributions}

Key: (1) project conception, (2) project design, (3) data acquisition, (4) data analysis, (5) manuscript drafting, and (6) manuscript revision. Individual author contributions are as follows - GMS: 1, 2, 3, 4, 5, 6; AT-W: 2, 4, 5, 6; NL: 2, 3, 4, 6; RTJ: 3, 4, 6; JCK: 3, 4, 6; JMF: 2, 4, 6; MA: 3, 4, 6; LFB: 3, 6; J-VC: 3, 6; WTC: 3, 6; BVN: 3, 6; JHS: 3, 6; SHP: 3, 6; S-HP: 3, 4, 6; CS: 4, 6; MSL: 4, 6; KC: 4, 6; ART: 2, 4, 6; PVH: 2, 4, 6; AOS-R: 3, 6; TTB: 4, 6; SLC: 4, 6; MPH: 2, 3, 4, 6; SS: 2, 3, 4, 6; DNL: 2, 3, 4, 6; FGB: 2, 3, 6; MM: 2, 4, 5, 6; GG: 2, 4, 5, 6; PKB: 1, 2, 4, 5,6 and DPC: $1,2,4,5,6$. All authors have provided their approval of the final version of the manuscript. 
Authors' information

Matthew Meyerson, Gad Getz, Priscilla K Brastianos and Daniel P Cahill are co-senior authors.

\section{Acknowledgments}

This work was supported by the Massachusetts General Hospital NeuroOncology Fund for Genomic Discovery. GMS was supported by NIH National Institutes of Neurologic Disorders and Stroke R25NS065743 and American Brain Tumor Association Basic Research Fellowship supported by the Humor to Fight the Tumor Event Committee. DPC was supported by the Burroughs Wellcome Career Award. PKB was supported by the American Brain Tumor Association Basic Research Fellowship and Brain Science Foundation. The authors thank Othon Iliopoulos for helpful discussions and Michelle Toohey and Ariel Warren for clinical assistance.

\section{Author details \\ ${ }^{1}$ Departments of Neurosurgery, Massachusetts General Hospital, Boston, MA, USA. 2Departments of Pathology, Massachusetts General Hospital, Boston, MA, USA. ${ }^{3}$ Divisions of Neuro-Oncology, Massachusetts General Hospital, Boston, MA, USA. ${ }^{4}$ Departments of Hematology/Oncology, Massachusetts General Hospital, Boston, MA, USA. ${ }^{5}$ Cancer Program, Broad Institute, Cambridge, MA, USA. ${ }^{6}$ Department of Pathology, Brigham and Women's Hospital, Boston, USA. ${ }^{7}$ Departments of Neurosurgery, Seoul National University, Seoul, South Korea. ${ }^{8}$ Pathology, Seoul National University, Seoul, South Korea. ${ }^{9}$ Center for Cancer Genome Discovery, Dana Farber Cancer Institute, Boston, MA, USA. ${ }^{10}$ Medical Oncology, Dana Farber Cancer Institute, Boston, MA, USA.}

Received: 19 November 2014 Accepted: 25 November 2014 Published online: 24 December 2014

\section{References}

1. Park DM, Zhuang Z, Chen L, Szerlip N, Maric I, Li J, Sohn T, Kim SH, Lubensky IA, Vortmeyer AO, Rodgers GP, Oldfield EH, Lonser RR (2007) von Hippel-Lindau disease-associated hemangioblastomas are derived from embryologic multipotent cells. PLoS Med 4:e60. doi:10.1371/journal.pmed.0040060

2. Gijtenbeek JMM, Jacobs B, Sprenger SHE, Eleveld MJ, van Kessel AG, Kros JM, Sciot R, van Calenbergh F, Wesseling P, Jeuken JWM (2002) Analysis of von hippel-lindau mutations with comparative genomic hybridization in sporadic and hereditary hemangioblastomas: possible genetic heterogeneity. J Neurosurg 97:977-982. doi:10.3171/jns.2002.97.4.0977

3. Gläsker S, Bender BU, Apel TW, van Velthoven V, Mulligan LM, Zentner J, Neumann HP (2001) Reconsideration of biallelic inactivation of the VHL tumour suppressor gene in hemangioblastomas of the central nervous system. J Neurol Neurosurg Psychiatry 70:644-648

4. Kim WY (2004) Role of VHL gene mutation in human cancer. J Clin Oncol 22:4991-5004. doi:10.1200/JCO.2004.05.061

5. Tse JY, Wong JH, Lo KW, Poon WS, Huang DP, Ng HK (1997) Molecular genetic analysis of the von Hippel-Lindau disease tumor suppressor gene in familial and sporadic cerebellar hemangioblastomas. Am J Clin Pathol 107:459-466

6. Kanno H, Kondo K, Ito S, Yamamoto I, Fujii S, Torigoe S, Sakai N, Hosaka M, Shuin T, Yao M (1994) Somatic mutations of the von Hippel-Lindau tumor suppressor gene in sporadic central nervous system hemangioblastomas. Cancer Res 54:4845-4847

7. Oberstrass J, Reifenberger G, Reifenberger J, Wechsler W, Collins VP (1996) Mutation of the Von Hippel-Lindau tumour suppressor gene in capillary haemangioblastomas of the central nervous system. J Pathol 179:151-156

8. Olschwang S, Richard S, Boisson C, Giraud S, Laurent-Puig P, Resche F, Thomas G (1998) Germline mutation profile of the VHL gene in von Hippel-Lindau disease and in sporadic hemangioblastoma. Hum Mutat 12:424-430. doi:10.1002/(SICI)1098-1004(1998)12:6<424::AID-HUMU9>3.0.CO;2-H

9. Lee JY, Dong SM, Park WS, Yoo NJ, Kim CS, Jang JJ, Chi JG, Zbar B, Lubensky IA, Linehan WM, Vortmeyer AO, Zhuang Z (1998) Loss of heterozygosity and somatic mutations of the VHL tumor suppressor gene in sporadic cerebellar hemangioblastomas. Cancer Res 58:504-508

10. Lemeta S, Pylkkänen L, Sainio M, Niemelä M, Saarikoski S, Husgafvel-Pursiainen K, Böhling T (2004) Loss of heterozygosity at $6 \mathrm{q}$ is frequent and concurrent with $3 p$ loss in sporadic and familial capillary hemangioblastomas. J Neuropathol Exp Neurol 63:1072-1079
11. Nickerson ML, Jaeger E, Shi Y, Durocher JA, Mahurkar S, Zaridze D, Matveev V, Janout V, Kollarova H, Bencko V, Navratilova M, Szeszenia-Dabrowska N, Mates D, Mukeria A, Holcatova I, Schmidt LS, Toro JR, Karami S, Hung R, Gerard GF, Linehan WM, Merino M, Zbar B, Boffetta P, Brennan P, Rothman N Chow W-H, Waldman FM, Moore LE (2008) Improved identification of von Hippel-Lindau gene alterations in clear cell renal tumors. Clin Cancer Res 14:4726-4734. doi:10.1158/1078-0432.CCR-07-4921

12. Moore LE, Nickerson ML, Brennan P, Toro JR, Jaeger E, Rinsky J, Han SS, Zaridze D, Matveev V, Janout V, Kollarova H, Bencko V, Navratilova M, Szeszenia-Dabrowska N, Mates D, Schmidt LS, Lenz P, Karami S, Linehan WM, Merino M, Chanock S, Boffetta P, Chow W-H, Waldman FM, Rothman N (2011) Von Hippel-Lindau (VHL) inactivation in sporadic clear cell renal cancer: associations with germline VHL polymorphisms and etiologic risk factors. PLoS Genet 7:e1002312. doi:10.1371/journal.pgen.1002312

13. Creighton CJ, Morgan M, Gunaratne PH, Wheeler DA, Gibbs RA, Gordon Robertson A, Chu A, Beroukhim R, Cibulskis K, Signoretti S, Vandin Hsin-Ta Wu F, Raphael BJ, Verhaak RGW, Tamboli P, Torres-Garcia W, Akbani R, Weinstein JN, Reuter V, Hsieh JJ, Rose Brannon A, Ari Hakimi A, Jacobsen A, Ciriello G, Reva B, Ricketts CJ, Marston Linehan W, Stuart JM, Kimryn Rathmell W, Shen H, Laird PW, et al. (2013) Comprehensive molecular characterization of clear cell renal cell carcinoma. Nature 499:43-49. doi:10.1038/nature12222

14. Sato $Y$, Y Yoshizato T, Shiraishi $Y$, Maekawa S, Okuno Y, Kamura T, Shimamura T, Sato-Otsubo A, Nagae G, Suzuki H, Nagata Y, Yoshida K, Kon A, Suzuki Y, Chiba K, Tanaka H, Niida A, Fujimoto A, Tsunoda T, Morikawa T, Maeda D, Kume H, Sugano S, Fukayama M, Aburatani H, Sanada M, Miyano S, Homma Y, Ogawa S (2013) Integrated molecular analysis of clear-cell renal cell carcinoma. Nat Genet 45:860-867. doi:10.1038/ng.2699

15. Vortmeyer AO, Gnarra JR, Emmert-Buck MR, Katz D, Linehan WM, Oldfield EH, Zhuang Z (1997) von Hippel-Lindau gene deletion detected in the stromal cell component of a cerebellar hemangioblastoma associated with von Hippel-Lindau disease. Hum Pathol 28:540-543

16. McLendon R, Friedman A, Bigner D, Van Meir EG, Brat DJ, Mastrogianakis GM, Olson JJ, Mikkelsen T, Lehman N, Aldape K, Alfred Yung WK, Bogler O, VandenBerg S, Berger M, Prados M, Muzny D, Morgan M, Scherer S, Sabo A, Nazareth L, Lewis L, Hall O, Zhu Y, Ren Y, Alvi O, Yao J, Hawes A, Jhangiani S, Fowler G, San Lucas A, et al. (2008) Comprehensive genomic characterization defines human glioblastoma genes and core pathways. Nature 455:1061-1068. doi:10.1038/nature07385

17. Stransky N, Egloff AM, Tward AD, Kostic AD, Cibulskis K, Sivachenko A, Kryukov GV, Lawrence MS, Sougnez C, McKenna A, Shefler E, Ramos AH, Stojanov P, Carter SL, Voet D, Cortés ML, Auclair D, Berger MF, Saksena G, Guiducci C, Onofrio RC, Parkin M, Romkes M, Weissfeld JL, Seethala RR, Wang L, Rangel-Escareño C, Fernandez-Lopez JC, Hidalgo-Miranda A, Melendez-Zajgla J, et al. (2011) The mutational landscape of head and neck squamous cell carcinoma. Science 333:1157-1160. doi:10.1126/science.1208130

18. Muzny DM, Bainbridge MN, Chang K, Dinh HH, Drummond JA, Fowler G, Kovar CL, Lewis LR, Morgan MB, Newsham IF, Reid JG, Santibanez J, Shinbrot E, Trevino LR, Wu Y-Q, Wang M, Gunaratne P, Donehower LA, Creighton CJ, Wheeler DA, Gibbs RA, Lawrence MS, Voet D, Jing R, Cibulskis K, Sivachenko A, Stojanov P, McKenna A, Lander ES, Gabriel S, et al. (2012) Comprehensive molecular characterization of human colon and rectal cancer. Nature 487:330-337. doi:10.1038/nature11252

19. Brastianos PK, Taylor-Weiner A, Manley PE, Jones RT, Dias-Santagata D, Thorner AR, Lawrence MS, Rodriguez FJ, Bernardo LA, Schubert L, Sunkavalli A, Shillingford N, Calicchio ML, Lidov HGW, Taha H, Martinez-Lage M, Santi M, Storm PB, Lee JYK, Palmer JN, Adappa ND, Scott RM, Dunn IF, Laws ER, Stewart C, Ligon KL, Hoang MP, Van Hummelen P, Hahn WC, Louis DN, et al. (2014) Exome sequencing identifies BRAF mutations in papillary craniopharyngiomas. Nat Genet 46:161-165. doi:10.1038/ng.2868

20. Wood LD, Parsons DW, Jones S, Lin J, Sjöblom T, Leary RJ, Shen D, Boca SM, Barber T, Ptak J, Silliman N, Szabo S, Dezso Z, Ustyanksky V, Nikolskaya T, Nikolsky Y, Karchin R, Wilson PA, Kaminker JS, Zhang Z, Croshaw R, Willis J, Dawson D, Shipitsin M, Willson JKV, Sukumar S, Polyak K, Park BH, Pethiyagoda CL, Pant PVK, et al. (2007) The genomic landscapes of human breast and colorectal cancers. Science 318:1108-1113. doi:10.1126/science.1145720

21. Meyerson M, Gabriel S, Getz G (2010) Advances in understanding cancer genomes through second-generation sequencing. Nat Rev Genet 11:685-696. doi:10.1038/nrg2841

22. Carter SL, Cibulskis K, Helman E, McKenna A, Shen H, Zack T, Laird PW, Onofrio RC, Winckler W, Weir BA, Beroukhim R, Pellman D, Levine DA, 
Lander ES, Meyerson M, Getz G (2012) Absolute quantification of somatic DNA alterations in human cancer. Nat Biotechnol 30:413-421. doi:10.1038/nbt.2203

23. Vortmeyer AO, Frank S, Jeong S-Y, Yuan K, Ikejiri B, Lee Y-S, Bhowmick $D$, Lonser RR, Smith R, Rodgers G, Oldfield EH, Zhuang Z (2003) Developmental arrest of angioblastic lineage initiates tumorigenesis in von Hippel-Lindau disease. Cancer Res 63:7051-7055

24. Vogeli KM, Jin S-W, Martin GR, Stainier DYR (2006) A common progenitor for haematopoietic and endothelial lineages in the zebrafish gastrula. Nature 443:337-339. doi:10.1038/nature05045

25. Zhuang Z, Frerich JM, Huntoon K, Yang C, Merrill MJ, Abdullaev Z, Pack SD, Shively SB, Stamp G, Lonser RR (2014) Tumor derived vasculogenesis in von Hippel-Lindau disease-associated tumors. Sci Rep 4:4102. doi: 10.1038/srep04102

26. Brastianos PK, Horowitz PM, Santagata S, Jones RT, McKenna A, Getz G, Ligon KL, Palescandolo E, Van Hummelen P, Ducar MD, Raza A, Sunkavalli A, Macconaill LE, Stemmer-Rachamimov AO, Louis DN, Hahn WC, Dunn IF, Beroukhim R (2013) Genomic sequencing of meningiomas identifies oncogenic SMO and AKT1 mutations. Nat Genet 45:285-289. doi:10.1038/ng.2526

27. Lawrence MS, Stojanov P, Polak P, Kryukov GV, Cibulskis K, Sivachenko A, Carter SL, Stewart C, Mermel CH, Roberts SA, Kiezun A, Hammerman PS, McKenna A, Drier Y, Zou L, Ramos AH, Pugh TJ, Stransky N, Helman E, Kim J, Sougnez C, Ambrogio L, Nickerson E, Shefler E, Cortés ML, Auclair D, Saksena G, Voet D, Noble M, DiCara D, et al. (2013) Mutational heterogeneity in cancer and the search for new cancer-associated genes. Nature 499:214-218. doi:10.1038/nature12213

28. McKenna A, Hanna M, Banks E, Sivachenko A, Cibulskis K, Kernytsky A, Garimella K, Altshuler D, Gabriel S, Daly M, DePristo MA (2010) The Genome Analysis Toolkit: a MapReduce framework for analyzing next-generation DNA sequencing data. Genome Res 20:1297-1303. doi:10.1101/gr.107524.110

29. Cibulskis K, Lawrence MS, Carter SL, Sivachenko A, Jaffe D, Sougnez C, Gabriel S, Meyerson M, Lander ES, Getz G (2013) Sensitive detection of somatic point mutations in impure and heterogeneous cancer samples. Nat Biotechnol 31:213-219. doi:10.1038/nbt.2514

30. Berger MF, Lawrence MS, Demichelis F, Drier Y, Cibulskis $K$, Sivachenko AY, Sboner A, Esgueva R, Pflueger D, Sougnez C, Onofrio R, Carter SL, Park K, Habegger L, Ambrogio L, Fennell T, Parkin M, Saksena G, Voet D, Ramos AH, Pugh TJ, Wilkinson J, Fisher S, Winckler W, Mahan S, Ardlie K, Baldwin J, Simons JW, Kitabayashi N, MacDonald TY, et al. (2011) The genomic complexity of primary human prostate cancer. Nature 470:214-220. doi:10.1038/nature09744

31. Ye K, Schulz MH, Long Q, Apweiler R, Ning Z (2009) Pindel: a pattern growth approach to detect break points of large deletions and medium sized insertions from paired-end short reads. Bioinformatics 25:2865-2871. doi: 10.1093/bioinformatics/btp394

32. Costello M, Pugh TJ, Fennell TJ, Stewart C, Lichtenstein L, Meldrim JC, Fostel JL, Friedrich DC, Perrin D, Dionne D, Kim S, Gabriel SB, Lander ES, Fisher S, Getz G (2013) Discovery and characterization of artifactual mutations in deep coverage targeted capture sequencing data due to oxidative DNA damage during sample preparation. Nucleic Acids Res 41:e67. doi: 10.1093/nar/gks1443

33. Lawrence MS, Stojanov P, Mermel CH, Robinson JT, Garraway LA, Golub TR, Meyerson M, Gabriel SB, Lander ES, Getz G (2014) Discovery and saturation analysis of cancer genes across 21 tumour types. Nature 505:495-501. doi:10.1038/nature12912

34. Drier Y, Lawrence MS, Carter SL, Stewart C, Gabriel SB, Lander ES, Meyerson M, Beroukhim R, Getz G (2012) Somatic rearrangements across cancer reveal classes of samples with distinct patterns of DNA breakage and rearrangementinduced hypermutability. Genome Res 23:228-235. doi:10.1101/gr.141382.112

35. Clark VE, Erson-Omay EZ, Serin A, Yin J, Cotney J, Ozduman K, Avşar T, Li J, Murray PB, Henegariu O, Yilmaz S, Günel JM, Carrión-Grant G, Yilmaz B, Grady C, Tanrikulu B, Bakircioğlu M, Kaymakçalan H, Caglayan AO, Sencar L, Ceyhun E, Atik AF, Bayri Y, Bai H, Kolb LE, Hebert RM, Omay SB, Mishra-Gorur K, Choi M, Overton JD, et al. (2013) Genomic analysis of non-NF2 meningiomas reveals mutations in TRAF7, KLF4, AKT1, and SMO. Science 339:1077-1080. doi:10.1126/science.1233009

36. Gläsker S, Li J, Xia JB, Okamoto H, Zeng W, Lonser RR, Zhuang Z, Oldfield EH, Vortmeyer AO (2006) Hemangioblastomas share protein expression with embryonal hemangioblast progenitor cell. Cancer Res 66:4167-4172. doi: 10.1158/0008-5472.CAN-05-3505

37. Lancrin C, Sroczynska P, Stephenson C, Allen T, Kouskoff V, Lacaud G (2009) The haemangioblast generates haematopoietic cells through a haemogenic endothelium stage. Nature 457:892-895. doi:10.1038/nature07679
38. Iliopoulos O, Levy AP, Jiang C, Kaelin WG, Goldberg MA (1996) Negative regulation of hypoxia-inducible genes by the von Hippel-Lindau protein Proc Natl Acad Sci U S A 93:10595-10599

39. Liotta LA, Kohn EC (2001) The microenvironment of the tumour-host interface. Nature 411:375-379. doi: 10.1038/35077241

40. Thomas RK, Nickerson E, Simons JF, Jänne PA, Tengs T, Yuza Y, Garraway LA, LaFramboise T, Lee JC, Shah K, O'Neill K, Sasaki H, Lindeman N, Wong K-K, Borras AM, Gutmann E, Dragnev KH, DeBiasi R, Chen T-H, Glatt KA, Greulich H, Desany B, Lubeski CK, Brockman W, Alvarez P, Hutchison SK, Leamon JH, Ronan MT, Turenchalk GS, Egholm M, et al. (2006) Sensitive mutation detection in heterogeneous cancer specimens by massively parallel picoliter reactor sequencing. Nat Med 12:852-855. doi:10.1038/nm1437

41. Sausen M, Leary RJ, Jones S, Wu J, Reynolds CP, Liu X, Blackford A, Parmigiani G, Diaz LA, Jr, Papadopoulos N, Vogelstein B, Kinzler KW, Velculescu VE, Hogarty MD (2013) Integrated genomic analyses identify ARID1A and ARID1B alterations in the childhood cancer neuroblastoma. Nat Genet 45:12-17. doi:10.1038/ng.2493

42. Shain AH, Giacomini CP, Matsukuma K, Karikari CA, Bashyam MD, Hidalgo M, Maitra A, Pollack JR (2012) Convergent structural alterations define SWItch/ Sucrose NonFermentable (SWI/SNF) chromatin remodeler as a central tumor suppressive complex in pancreatic cancer. Proc Natl Acad Sci U S A 109:E252-E259. doi:10.1073/pnas.1114817109

43. Fujimoto A, Totoki Y, Abe T, Boroevich KA, Hosoda F, Nguyen HH, Aoki M, Hosono N, Kubo M, Miya F, Arai Y, Takahashi H, Shirakihara T, Nagasaki M, Shibuya T, Nakano K, Watanabe-Makino K, Tanaka H, Nakamura H, Kusuda J, Ojima H, Shimada K, Okusaka T, Ueno M, Shigekawa Y, Kawakami Y, Arihiro K, Ohdan H, Gotoh K, Ishikawa O, et al. (2012) Whole-genome sequencing of liver cancers identifies etiological influences on mutation patterns and recurrent mutations in chromatin regulators. Nat Genet 44:760-764. doi:10.1038/ng.2291

44. Helming KC, Wang X, Wilson BG, Vazquez F, Haswell JR, Manchester HE, Kim Y, Kryukov GV, Ghandi M, Aguirre AJ, Jagani Z, Wang Z, Garraway LA, Hahn WC, Roberts CWM (2014) ARID1B is a specific vulnerability in ARID1A-mutant cancers. Nat Med 20:251-254. doi:10.1038/nm.3480

45. Marusyk A, Tabassum DP, Altrock PM, Almendro V, Michor F, Polyak K (2014) Non-cell-autonomous driving of tumour growth supports sub-clonal heterogeneity. Nature. doi:10.1038/nature13556

46. Cleary AS, Leonard TL, Gestl SA, Gunther EJ (2014) Tumour cell heterogeneity maintained by cooperating subclones in Wnt-driven mammary cancers. Nature 508:113-117. doi:10.1038/nature13187

47. Bosniak MA (1986) The current radiological approach to renal cysts. Radiology 158:1-10. doi:10.1148/radiology.158.1.3510019

48. Riklin C, Seystahl K, Hofer S, Happold C, Winterhalder R, Weller M (2012) Antiangiogenic treatment for multiple CNS hemangioblastomas. Onkologie 35:443-445. doi: 10.1159/000341075

49. Omar Al (2012) Bevacizumab for the treatment of surgically unresectable cervical cord hemangioblastoma: a case report. J Med Case Reports 6:238. do:10.1186/1752-1947-6-238

\section{Submit your next manuscript to BioMed Central and take full advantage of:}

- Convenient online submission

- Thorough peer review

- No space constraints or color figure charges

- Immediate publication on acceptance

- Inclusion in PubMed, CAS, Scopus and Google Scholar

- Research which is freely available for redistribution 